\title{
DESEMPENHO AGRONÔMICO DE BANANEIRAS MICROPROPAGADAS EM BOTUCATU-SP1
}

\author{
SARITA LEONEL ${ }^{2}$, EVERALDO MARIANO GOMES ${ }^{3}$, CARLOS JORGE PEDROSO ${ }^{4}$
}

\begin{abstract}
RESUMO - O trabalho teve como objetivo avaliar o desempenho agronômico de cultivares de bananeira 'Prata-anã', 'Maçã’ e 'Nanicão', no município de Botucatu-SP. As mudas provenientes de micropropagação foram aclimatadas em estufa durante noventa dias e, posteriormente, plantadas no campo, conforme as recomendações técnicas para a cultura. Foram avaliadas características de crescimento, como número de dias do plantio à colheita, número de folhas ativas, altura de plantas e diâmetro do pseudocaule, medidas na época de emissão da inflorescência. Também foram mensuradas características de produção, entre as quais o número de frutos, diâmetro, comprimento e peso da segunda penca, peso total das pencas e número de frutos por cacho, na época da colheita. Os resultados obtidos evidenciaram que o ciclo cultural médio variou com as cultivares, sendo de 416 dias, contados do plantio à colheita para a cv 'Nanicão', que foi a mais precoce, seguido da 'Prata-anã' (434 dias) e da 'Maçã' (437 dias). As três cultivares apresentaram produtividade estimada no primeiro ciclo (planta-mãe) de 30,56 t.ha' ${ }^{-1}$; 19,50 t.ha ${ }^{-1}$ e 14,37 t.ha ${ }^{-1}$, respectivamente, para 'Nanicão', 'Prata-anã' e 'Maçã'. Houve correlação positiva entre algumas características de crescimento e produção.
\end{abstract}

Termos de indexação: Musa spp, crescimento, desenvolvimento, produção.

\section{AGRONOMIC CHARACTERISTICS OF MICROPROPAGATED BANANAS FROM BOTUCATU}

\begin{abstract}
The research had as purpose to evaluate the agronomic characteristics of the bananas' cultivars 'Prata-anã' (group AAB), 'Maçã' (group $\mathrm{AAB}$ ) and 'Nanicão' (group AAA) under the conditions of Botucatu city, São Paulo state, Brazil. The plants origined by tissue culture were climatizated in greenhouse during 90 days and after they were planted in the yield. Were evaluated the growth parameters as days number between the planting until the harvest, leaf number, plants height and stem diameter at the flowering time. Also, were measured production parameters as fruits number, banana bunches number, fruits diameter, banana bunches weight, height and weight of second banana bunch and fruits number per cluster at the harvesting time. The results showed that the medium growing period until the harvest was about 416 days for the cv 'Nanicão'that was the earliest, followed by the cv 'Prata-anã' (434 days) and 'Maçã' (437 days). The tree cultivars showed estimated productions on the first period (mother plant) of 30,56 t.ha ${ }^{-1} ; 19,50$ t.ha $^{-1}$ and 14,37 t.ha' ${ }^{-1}$ for the cv 'Nanicão', 'Prata-anã' and 'Maçã', respectively. There was positive correlation between the growth and the production.
\end{abstract}

Index terms: Musa spp, growing, development, production.

\section{INTRODUÇÃO}

Originária da Índia, a banana é uma das frutas há mais tempo consumida no mundo. O cultivo comercial teve início em sua própria terra de origem, as úmidas selvas da Índia e a península da Indochina (Almeida et al., 2000).

O Brasil ocupa o segundo lugar na produção mundial de bananas, com 9,8\% do volume total produzido, numa área de 480.814 hectares, mas tem pequena participação no mercado externo, porque a fruta é consumida quase que na sua totalidade (98\%) internamente. O Estado de São Paulo, com uma área colhida de 51.740 hectares, contribui com a maior parte da produção brasileira, por ter sido pioneiro na implantação de culturas comerciais (Agrianual, 2001).

Nas regiões Sul e Sudeste, as variedades do subgrupo Cavendish ('Nanica' e 'Nanicão') são as mais expressivas, seguidas da cultivar 'Prata'. A cultivar 'Maçã', embora de grande aceitação pelos consumidores, vem enfrentando problemas fitossanitários que praticamente inviabilizam o cultivo comercial por muito tempo.

O sistema de propagação empregado convencionalmente, mediante mudas, vem permitindo a disseminação de doenças e pragas para novas áreas (Souza et al., 2000). Diante disso, o sistema de micropropagação vem sendo utilizado para produção de mudas de bananeira a nível comercial. Contudo, ainda existem poucos dados sobre o comportamento agronômico de mudas oriundas deste sistema no campo. De acordo com o relato de Teixeira (2000), as mudas micropropagadas destacam-se por serem mais produtivas no primeiro ciclo do que as convencionais. O peso dos cachos um pouco mais altos associados à precocidade fazem com que o rendimento de frutos/ha/ano seja quase sempre superior com o uso de mudas micropropagadas. Contrariamente, Pereira et al. (1998), avaliando o comportamento vegetativo e produtivo das cultivares 'Prata', 'Prata-anã' e 'Mysore', oriundas de dois métodos de propagação (mudas de cultura de tecidos e mudas convencionais tipo "chifre" e pedaços de rizoma), não confirmaram a precocidade da muda obtida por cultura de tecidos.

Nesse contexto, considerando-se a importância da cultura da bananeira para o Estado de São Paulo e a expansão dos cultivos para regiões não tradicionais, como o centro-oeste paulista e o emprego crescente pelos produtores de mudas micropropagadas, o presente trabalho teve como objetivo avaliar o desempenho agronômico de cultivares de bananeira 'Prata-anã', 'Maçã' e 'Nanicão', no município de Botucatu-SP.

\section{MATERIALEMÉTODOS}

O experimento foi instalado em área do pomar do Departamento de Produção Vegetal da Faculdade de Ciências Agronômicas da UNESP, Câmpus de Botucatu-SP, localizada nas coordenadas geográficas de $22^{\circ} 52^{\prime} 47^{\prime \prime}$ latitude S, $48^{\circ} 25^{\prime} 12^{\prime \prime}$ longitude W e altitude de $810 \mathrm{~m}$. O tipo climático predominante no local é o temperado, sem inverno seco, sendo a média das temperaturas mínimas de $18^{\circ} \mathrm{C}$ e a das máximas de $22^{\circ} \mathrm{C}$, com precipitação média anual de $1.314 \mathrm{~mm}$ (Curi, 1972). O solo da área foi caracterizado como Nitossolo vermelho, segundo critérios da Embrapa (1999).

As mudas produzidas pelo processo de micropropagação em laboratório e aclimatizadas em estufa possuíam certificação de sanidade vegetal, estando livres de pragas e doenças (www.multiplanta.com.br).

\footnotetext{
${ }^{1}$ (Trabalho 165/2003). Recebido: 31/10/2003. Aceito para publicação: 29/06/2004.

${ }^{2}$ Prof $^{\mathrm{a}}$ Dri $^{\mathrm{a}}$. Departamento de Produção Vegetal. Faculdade de Ciências Agronômicas. UNESP. Cx Postal 237, CEP 18603-970. Botucatu-SP. sarinel@ fca.unesp.br Tel: 014-38117172 e 38117203.

${ }^{3}$ Eng $^{\circ} \mathrm{Agr}^{\circ}$. Msc. Doutorando em Irrigação e Drenagem. FCA/UNESP/Botucatu. Prof. Escola Agrotécnica Federal de Sousa-PB. Tel: (83) 5222727.

${ }^{4}$ Técnico Agrícola. Bolsista da FAPESP. Faculdade de Ciências Agronômicas. UNESP. Cx Postal, 237, CEP 18603-970. Botucatu-SP. Tel: 014-38117172 e 38117203.
} 
Na ocasião da aquisição, as mudas apresentavam altura da parte aérea entre 10 e $15 \mathrm{~cm}$ e torrão de $6 \mathrm{~cm}$. A seguir, foram transplantadas para sacos de polietileno preto de $18,5 \times 10,0 \mathrm{~cm}$, preenchidas com mistura realizada com $1 / 3$ de terra de subsolo, $1 / 3$ de vermiculita e $1 / 3$ de esterco de curral curtido. As plantas permaneceram durante 90 dias em estufa e, após passado este período, foram transplantadas para o campo, em área previamente preparada, calcareada e adubada, conforme resultado de análise de solo prévia e seguindo as recomendações técnicas da cultura (Boletim Técnico $\mathrm{n}^{\circ} 100$ IAC, 1996), num espaçamento de 2,5 x 2,5 m, com uma área de $6,25 \mathrm{~m}^{2} /$ planta.

Durante o primeiro ciclo de produção (planta-mãe), as plantas receberam os seguintes tratos culturais: irrigação complementar, controle de plantas daninhas, desbaste, retirada de folhas secas, eliminação do coração, retirada dos pistilos e corte do pseudocaule após a colheita.

O delineamento experimental empregado foi o inteiramente casualizado, com 3 tratamentos, correspondentes às cultivares de bananeiras estudadas, 16 repetições e 1 planta (família) útil por unidade experimental, completamente rodeada por 4 plantas (famílias) bordadura. Foi utilizado o método das estatísticas descritivas, através do cálculo das médias e desvio-padrão, para a caracterização das cultivares. Posteriormente, foram estabelecidas possíveis correlações entre medidas de desenvolvimento vegetativo e produção (Kronka e Banzatto, 1992).

Avaliaram-se características de crescimento medidas na emissão da inflorescência, conforme segue: número de dias do plantio à emissão da inflorescência, número de dias do plantio à colheita, número de folhas ativas, altura de plantas (medida do nível do solo até o nível superior da roseta foliar) e diâmetro do pseudocaule. Também foram mensuradas características de produção, como o número de pencas, número de frutos, diâmetro, comprimento e peso da segunda penca (Rodrigues et al., 1998), o peso total das pencas e o número de frutos por cacho, avaliados na época da colheita.

\section{RESULTADOS E DISCUSSÃO}

A duração dos ciclos vegetativo e produtivo das cultivares de bananeira revelou que a cv 'Nanicão' foi a mais precoce, com duração média total do primeiro ciclo de 416 dias, seguida da cv 'Prata-anã', com 434 dias e da cv 'Maçã', com 437 dias, o que pode ser considerado como início de produção precoce, quando comparado com relatos de pequenos produtores rurais da região de Botucatu-SP, que utilizam mudas de rizoma brotado para o plantio. Segundo Kluge (1999), que avaliou o primeiro ciclo produtivo da bananeira 'Nanicão', as mudas micropropagadas foram as que apresentaram colheita mais tardia, com 511,92 dias do plantio até a colheita, comparadas com 483,73 dias dos pedaços de rizoma e com outros sistemas de cultivo, como"chifrinho", "chifrão" (brotações laterais com folhas lanceoladas) e "guarda-chuva" (brotações separadas da planta-mãe, com folhas normais). Estes resultados foram confirmados anteriormente por Pradeed et al. (1992), que constataram florescimento tardio de mudas oriundas de micropropagação, quando comparadas com as mudas convencionais. No entanto, estes resultados são contrários aos obtidos por Vulsteke \& Ortiz (1996), que observaram o florescimento precoce. No que se refere à produtividade, embora existam resultados indicando que as mudas micropropagadas podem ser mais produtivas que as convencionais (Drew \& Smith, 1990), outros estudos mostram um comportamento semelhante dos dois tipos de materiais de plantio (Souza et al., 2000).

Com relação ao ciclo da cultura, em algumas regiões produtoras de bananas do Estado de Minas Gerais, Pereira et al. (1998), em Jaíba (região norte de Minas Gerais), e Salomão et al. (1998), em Visconde do Rio Branco (região da zona da mata de Minas Gerais), avaliando o comportamento da cv 'Prata-anã' em condições de sequeiro, relatam que o ciclo total foi, respectivamente, de 411 e 520 dias. No presente trabalho, realizado com irrigação complementar, verificou-se uma diminuição neste ciclo, para a região de Botucatu-SP, quando comparado à outra região produtora do Estado de São Paulo (oeste paulista), que foi de 633 dias com irrigação e 646 dias em condições de sequeiro para a cv 'Prata-anã' (Foltran et al., 1998).

Martins et al. (1998), estudando o comportamento de bananeiras do subgrupo 'Prata' nas condições do Vale do Jequitinhonha, em Minas Gerais, concluíram que os resultados da primeira colheita permitiram deduzir que as duas variedades ('Prata-anã' e 'Mineira') testadas apresentaram potencial para a região com comportamentos similares, com ligeira vantagem para a 'Prata-anã' em relação à uniformidade de floração.

Os resultados obtidos neste experimento evidenciaram correlações positivas e significativas entre o número de folhas, altura de plantas e diâmetro do pseudocaule, com o peso das pencas, peso dos frutos da segunda penca e o número de frutos da segunda penca para as cultivares 'Nanicão' e 'Prata-anã' (Tabelas 1 e 3). Para a cv 'Maçã', as correlações positivas e significativas estatisticamente foram entre o número de folhas e o peso, diâmetro e comprimento dos frutos da segunda penca (Tabela 2). Também foram positivas as correlações entre altura de plantas e o peso das pencas, e o número de frutos por cacho

TABELA 1 - Resultados obtidos para Coeficiente de Correlação de Pearson $\left(\mathrm{r}^{2}\right)$, avaliado entre as características de crescimento e produção de bananeira cv 'Nanicão'. FCA/UNESP/Botucatu. 2003.

\begin{tabular}{|c|c|c|c|c|c|c|c|}
\hline $\begin{array}{l}\text { Coeficiente de } \\
\text { Correlação }\end{array}$ & & & & Característica & de produção & & \\
\hline $\begin{array}{l}\text { Caracterísitcas de } \\
\text { crescimento }\end{array}$ & $\begin{array}{c}\text { Número de } \\
\text { pencas }\end{array}$ & $\begin{array}{c}\text { Peso dos frutos } \\
\text { da } 2^{\mathrm{a}} \text { penca }\end{array}$ & $\begin{array}{c}\text { Peso das } \\
\text { pencas }\end{array}$ & $\begin{array}{c}\text { Número de } \\
\text { frutos por cacho }\end{array}$ & $\begin{array}{c}\text { Número de } \\
\text { frutos } 2^{\mathrm{a}} \text { penca }\end{array}$ & $\begin{array}{l}\text { Diâmetro dos } \\
\text { frutos } 2^{\mathrm{a}} \text { penca }\end{array}$ & $\begin{array}{l}\text { Comprimento dos } \\
\text { frutos } 2^{\mathrm{a}} \text { penca }\end{array}$ \\
\hline Número de folhas & $0,0186 \mathrm{~ns}$ & $0,7533^{*}$ & $0,9620 *$ & $0,4110 \mathrm{~ns}$ & $0,6906 *$ & $0,5548 \mathrm{~ns}$ & $0,4443 \mathrm{~ns}$ \\
\hline Altura de plantas & $0,6161 *$ & $0,9332 *$ & $0,8790 *$ & $0,1672 \mathrm{~ns}$ & $0,9308 *$ & $0,2400 \mathrm{~ns}$ & $0,3906 \mathrm{~ns}$ \\
\hline Diâmetro do & $0,8771 *$ & $0,6625 *$ & $0,7625 *$ & $0,4376 \mathrm{~ns}$ & $0,8743 *$ & $0,8797 *$ & $0,3356 \mathrm{~ns}$ \\
\hline
\end{tabular}

pseudocaule

ns = não significativo $*$ = significativo a $5 \%$ de probabiliade

TABELA 2 - Resultados obtidos para Coeficiente de Correlação de Pearson $\left(r^{2}\right)$, avaliado entre as características de crescimento e produção de bananeira cv 'Maçã'. FCA/UNESP/Botucatu. 2003.

\begin{tabular}{|c|c|c|c|c|c|c|c|}
\hline $\begin{array}{l}\text { Coeficiente de } \\
\text { Correlação }\end{array}$ & & & & Características de & rodução & & \\
\hline $\begin{array}{l}\text { Caracterísitcas de } \\
\text { crescimento }\end{array}$ & $\begin{array}{c}\text { Número } \\
\text { de pencas }\end{array}$ & $\begin{array}{l}\text { Peso dos frutos } \\
\text { da } 2^{\mathrm{a}} \text { penca }\end{array}$ & $\begin{array}{l}\text { Peso das } \\
\text { pencas }\end{array}$ & $\begin{array}{c}\text { Número de } \\
\text { frutos por cacho }\end{array}$ & $\begin{array}{c}\text { Número de } \\
\text { frutos } 2^{\mathrm{a}} \text { penca }\end{array}$ & $\begin{array}{l}\text { Diâmetro dos } \\
\text { frutos } 2^{\mathrm{a}} \text { penca }\end{array}$ & $\begin{array}{l}\text { Comprimento dos } \\
\text { frutos } 2^{\mathrm{a}} \text { penca }\end{array}$ \\
\hline Número de folhas & $0,1783 \mathrm{~ns}$ & $0,8364 *$ & $0,5269 \mathrm{~ns}$ & $0,3470 \mathrm{~ns}$ & $0,5860 \mathrm{~ns}$ & $0,7158 *$ & $0,8803 *$ \\
\hline Altura de plantas & $0,2705 \mathrm{~ns}$ & $0,0547 \mathrm{~ns}$ & $0,8338 *$ & $0,8825 *$ & $0,0873 \mathrm{~ns}$ & $0,5973 \mathrm{~ns}$ & $0,7199 *$ \\
\hline Diâmetro do & $0,4401 \mathrm{~ns}$ & $0,5481 \mathrm{~ns}$ & $0,3482 \mathrm{~ns}$ & $0,9976 *$ & $0,3558 \mathrm{~ns}$ & $0,5348 \mathrm{~ns}$ & $0,1205 \mathrm{~ns}$ \\
\hline
\end{tabular}

pseudocaule

ns = não significativo $*=$ significativo a $5 \%$ de probabiliade 
TABELA 3 - Resultados obtidos para Coeficiente de Correlação de Pearson $\left(\mathrm{r}^{2}\right)$, avaliado entre as características de crescimento e produção de bananeira cv 'Prata-anã'. FCA/UNESP/Botucatu. 2003.

\begin{tabular}{|c|c|c|c|c|c|c|c|}
\hline $\begin{array}{l}\text { Coeficiente de } \\
\text { Correlação }\end{array}$ & & & & Características d & produção & & \\
\hline $\begin{array}{c}\text { Caracterísitcas de } \\
\text { crescimento }\end{array}$ & $\begin{array}{c}\text { Número de } \\
\text { pencas }\end{array}$ & $\begin{array}{c}\text { Peso dos frutos } \\
\text { da } 2^{\mathrm{a}} \text { penca }\end{array}$ & $\begin{array}{c}\text { Peso das } \\
\text { pencas }\end{array}$ & $\begin{array}{c}\text { Número de frutos } \\
\text { por cacho }\end{array}$ & $\begin{array}{c}\text { Número de } \\
\text { frutos } 2^{\mathrm{a}} \text { penca }\end{array}$ & $\begin{array}{l}\text { Diâmetro dos } \\
\text { frutos } 2^{\mathrm{a}} \text { penca }\end{array}$ & $\begin{array}{l}\text { Comprimento dos } \\
\text { frutos } 2^{\mathrm{a}} \text { penca }\end{array}$ \\
\hline Número de folhas & $0,0186 \mathrm{~ns}$ & $0,7533 *$ & $0,9620 *$ & $0,4110 \mathrm{~ns}$ & $0,6906 *$ & $0,5548 \mathrm{~ns}$ & $0,4443 \mathrm{~ns}$ \\
\hline Altura de plantas & $0,6161 *$ & $0,9332 *$ & $0,8790 *$ & $0,1672 \mathrm{~ns}$ & $0,9308 *$ & $0,2400 \mathrm{~ns}$ & $0,3906 \mathrm{~ns}$ \\
\hline Diâmetro do & $0,8771 *$ & $0,6625 *$ & $0,7625 *$ & $0,4376 \mathrm{~ns}$ & $0,8743 *$ & $0,8797 *$ & $0,9269 *$ \\
\hline
\end{tabular}

ns = não significativo $*=$ significativo a $5 \%$ de probabiliade

(Tabela 2). Esses resultados permitem inferências sobre um bom crescimento e desenvolvimento das cultivares de bananeira, oriundas de mudas micropropagadas, na região de estudo, refletindo em correlações positivas e significativas com as características de produção.

Gaiva (1992), estudando o comportamento das plantas-matrizes de bananeira cultivares 'Farta-velhaco' (grupo AAB), 'Mysore' (AAB) e 'Nanicão' (AAA), observou que o maior número de folhas ativas, na época da colheita, correspondeu a cachos mais pesados nas cvs 'Mysore' e 'Nanicão'. Ainda segundo o mesmo autor, os pesos dos cachos não apresentaram correlação com a altura das plantas nas 3 cultivares, e também, nos perímetros dos pseudocaules nas cvs 'Farta-velhaco' e 'Nanicão'. Pereira et al. (1998), na mesma linha de pesquisa, obtiveram superioridade da cv 'Prata-anã' em relação à 'Prata' e 'Mysore', com maior peso do cacho e dos frutos, maior número de folhas funcionais, menores períodos vegetativo, produtivo e total. O peso médio dos frutos no primeiro ciclo foi de 115,62 g e do cacho foi de 11,61 kg na cv 'Prata-anã' .

Nas condições edafoclimáticas do município de Botucatu-SP, o peso médio do cacho foi de 12,20 kg, para 'Prata-anã', 8,93 kg para 'Maçã' e 19,06 kg para 'Nanicão'(Tabela 4). A produtividade média estimada foi de 30,56; 14,37 e 19,50 t.ha-1 ${ }^{-1}$, respectivamente, para as cvs 'Nanicão', 'Maçã' e 'Prata-anã' (Tabela 4), permitindo inferir sobre o comportamento superior da bananeira 'Nanicão' em precocidade dos ciclos vegetativo e produtivo e nas características de crescimento e produção, corroborando os resultados obtidos por Brechbuelber \& Couto (1996), os quais relataram que a cv 'Nanicão' apresentou um menor ciclo entre o plantio e a colheita, bem como um menor tempo entre a emissão do cacho e sua colheita. O número de frutos por cacho, o peso

TABELA 4 - Resultados obtidos para número médio de folhas, altura média de plantas, diâmetro médio do pseudocaule, número médio de pencas, número médio de frutos por cacho, peso médio das pencas, número médio de frutos, diâmetro médio dos frutos, comprimento médio dos frutos e peso médio dos frutos da segunda penca de cultivares de bananeira 'Nanicão', 'Maçã' e 'Prata-anã', em Botucatu-SP. FCA/ UNESP/2003.

\begin{tabular}{|c|c|c|c|c|c|c|c|c|c|c|c|}
\hline $\begin{array}{c}\text { Parâmetros } \\
\text { avaliados }\end{array}$ & $\begin{array}{l}\text { Número de } \\
\text { folhas }\end{array}$ & $\begin{array}{l}\text { Altura de } \\
\text { plantas } \\
\text { (m) }\end{array}$ & $\begin{array}{l}\text { Diâmetro } \\
\text { do } \\
\text { pseudoca } \\
\text { ule }(\mathrm{cm})\end{array}$ & $\begin{array}{l}\text { Número } \\
\text { de pencas }\end{array}$ & $\begin{array}{l}\text { Número de } \\
\text { frutos por } \\
\text { cacho }\end{array}$ & $\begin{array}{l}\text { Peso das } \\
\text { pencas } \\
(\mathrm{Kg})\end{array}$ & $\begin{array}{c}\text { Número } \\
\text { de frutos } \\
\text { da } 2^{\mathrm{a}} \\
\text { penca }\end{array}$ & $\begin{array}{c}\text { Diâmetro } \\
\text { dos } \\
\text { frutos da } \\
2^{\mathrm{a}} \text { penca } \\
(\mathrm{mm})\end{array}$ & $\begin{array}{l}\text { Compri- } \\
\text { mento dos } \\
\text { frutos da } 2^{\mathrm{a}} \\
\text { penca }(\mathrm{cm})\end{array}$ & $\begin{array}{c}\text { Peso dos } \\
\text { frutos } \\
\text { da } 2^{\mathrm{a}} \\
\text { penca } \\
(\mathrm{Kg})\end{array}$ & $\begin{array}{l}\text { Produtivi- } \\
\text { dade } \\
\text { estimada } \\
\left(\text { t.ha }^{-1}\right)^{*}\end{array}$ \\
\hline Nanicão & $18,5 \quad 1,2$ & $2,1 \quad 0,1$ & $71,8 \quad 5,0$ & $8,9 \quad 0,5$ & $140,6 \quad 14,0$ & $19,1 \quad 2,9$ & $18,3 \quad 2,3$ & $32,8 \quad 1,9$ & $15,1 \quad 1,0$ & $3,0 \quad 0,6$ & $30,6 \quad 4,7$ \\
\hline $\mathrm{CV}(\%)$ & 6,4 & 6,8 & 7,0 & 5,1 & 9,9 & 15,5 & 12,6 & 5,9 & 6,4 & 20,9 & 15,2 \\
\hline Maçã & $17,0 \quad 1,5$ & $3,3 \quad 0,5$ & $72,9 \quad 2,6$ & $7,8 \quad 0,6$ & $106,8 \quad 11,8$ & $8,9 \quad 1,8$ & $14,5 \quad 2,0$ & $30,2 \quad 2,6$ & $12,1 \quad 1,2$ & $1,3 \quad 0,5$ & $14,4 \quad 3,3$ \\
\hline CV (\%) & 8,9 & 14,64 & 3,5 & 7,2 & 11,1 & 20,0 & 13,7 & 8,7 & 9,6 & 36,6 & 23,1 \\
\hline Prata-anã & $19,5 \quad 1,6$ & $2,3 \quad 0,5$ & $70,9 \quad 4,6$ & $9,0 \quad 1,1$ & $120,6 \quad 17,6$ & $12,2 \quad 2,9$ & $10,6 \quad 2,6$ & $32,8 \quad 2,5$ & $12,6 \quad 0,9$ & $1,7 \quad 0,5$ & $19,5 \quad 4,6$ \\
\hline $\mathrm{CV}(\%)$ & 8,4 & 20,9 & 6,5 & 12,6 & 14,6 & 23,8 & 24,1 & 7,6 & 7,2 & 29,3 & 23,8 \\
\hline
\end{tabular}

$*$ = densidade de 1.600 plantas/ha

do cacho e das pencas foi maior na 'Nanicão', quando comparado com a 'Prata-anã' (Tabela 4). A produtividade estimada foi de 38 t.ha ${ }^{-1}$ na 'Nanicão' e 17 t.ha ${ }^{-1}$ na 'Prata-anã' (Tabela 4). No oeste paulista, Foltran et al. (1998) relataram produtividades médias no primeiro ciclo, com e sem irrigação, variando entre 8,9 e 16,9 t.ha' ${ }^{-1}$ nas bananeiras 'Nanicão', 'Nanicão jangada', 'Mysore' e 'Grand naine'.

\section{CONCLUSÕES}

1. As cultivares de bananeira 'Nanicão', 'Maçã' e 'Prata-anã', oriundas de mudas micropropagadas, apresentaram, no município de Botucatu-SP, o primeiro ciclo de produção (planta-mãe) variando entre 416 dias para a cv 'Nanicão', que foi a mais precoce, seguida da 'Prataanã' (434 dias) e da 'Maçã' (437 dias).

2. Houve correlações positivas entre características de crescimento e produção, que variaram conforme a cultivar, porém todas apresentaram boa precocidade e produtividade, para a região de BotucatuSP, permitindo a indicação do uso de mudas micropropagadas em culturas comerciais.

3. A cultivar 'Nanicão' apresentou o maior peso médio do cacho $(19,06 \mathrm{~kg})$ e a maior produtividade estimada $\left(30,56\right.$ t.ha $\left.^{-1}\right)$, seguida da
'Prata-anã', com peso médio do cacho de $12,20 \mathrm{~kg}$ e produtividade estimada de19,50 t.ha' ${ }^{-1}$. A cultivar 'Maçã' apresentou cachos com peso médio de $8,93 \mathrm{~kg}$ e produtividade estimada de 14,37 t.ha ${ }^{-1}$.

\section{REFERÊNCIAS BIBLIOGRÁFICAS}

AGRIANUAL 2001. Anuário Estatísitco da Agricultura Brasileira. São Paulo: FNP Consultoria e Comércio, 2002.

ALMEIDA, C.O. de; SOUZA, J. da S.; CORDEIRO, Z.J.M. Aspectos socioeconômicos. In: CORDEIRO, Z.J.M. Banana produção: aspectos técnicos. Brasília: Embrapa Comunicação para transferência de tecnologia, 2000, p. 10-11.

BRECHBUELBER, A.J.M.M.; COUTO, F.A.A. Avaliação do comportamento agronômico da bananeira (Musa spp) cvc. 'Nanicão' e 'Prata-anã' na microrregião de Viçosa, Minas Gerais. In: CONGRESSOBRASILEIRODEFRUTICULTURA, 14., 1996, Curitiba. Anais...Sociedade Brasileira de Fruticultura: 1996. p.74.

BOLETIM TÉCNICO DO INSTITUTO AGRONÔMICO: Campinas: Instituto Agronômico, 1996.

CURI, P.R. Relações entre evaporação média pelo tanque IA-58 e evapotranspiração calculada pelas equações de Thornthwaite $e$ 
Camargo, para o município de Botucatu. 1972. 88f. Tese (Doutorado) - Faculdade de Ciências Médicas e Biológicas de Botucatu, Universidade Estadual Paulista, Botucatu, 1972.

EMBRAPA. Centro Nacional de Pesquisa de Solos. Sistema brasileiro de classificação de solos. Rio de Janeiro, 1999. 412p.

FOLTRAN, D.E.; TEIXEIRA, L.A.J.; PIRES, R.C de;ZAMARIOLLI, E.R. Comportamento de sete cultivares de bananeira no Oeste Paulista. In: CONGRESSO BRASILEIRO DE FRUTICULTURA, 15., 1998, Poços de Caldas-MG, Resumos... Lavras. UFLA/SBF, 1998. p.127.

GAIVA, H.N. Avaliação de algumas características do desenvolvimento e da produção de três cultivares de bananeira (musa spp), na baixada cuiabana - MT. 1992. 103f. Doutorado (Produção vegetal) Faculdade de Ciências Agrárias e Veterinárias, Universidade Estadual Paulista, Jaboticabal,1992.

KLUGE, R.A. Densidade e sistema de espaçamento de bananeiras 'Nanicão' (Musa AAA subgrupo Cavendih). 1999. 105p. Tese (Doutorado em Fitotecnica) - Escola Superior de Agricultura Luiz de Queiroz, Universidade de São Paulo, Piracicaba, 1999.

KRONKA, S.N.; BANZATTO, D.A. Experimentação agrícola. Jaboticabal: FUNEP, 1992. 247p.

MARTINS, C.P.A; SILVA, AT.; PASQUAL, M. Avaliação do comportamento de bananeiras do subgrupo 'Prata' nas condições edafoclimáticas do vale do Jequitinhonha em Minas Gerais. In: CONGRESSO BRASILEIRO DEFRUTICULTURA, 15., 1998, Poços de Caldas. Anais... Sociedade Brasileira de Fruticultura e Universidade Federal de Lavras, 1998. p. 123.

PRADEED, K.P.; ZACHARIAH, G.; ESTELITTA, S.; SUMA, A. Field performance of banana tissue culture plants of variety Nendran (MusaAAB). South Indian Horticulture, Coimbatore, v.40, n.1, p.14, 1992.
PEREIRA, L.V.; REZENDE e SILVA, C.R. de; ALVARENGA, A.A. Comportamento de cultivares de bananeiras oriundas de mudas de cultura de tecidos e convencionais. In: CONGRESSO BRASILEIRO DE FRUTICUlTURA, 15., 1998, Poços de Caldas-MG. Anais... Sociedade Brasileira de Fruticultura e Universidade Federal de Lavras, 1998. p.125.

RODRIGUES, P.H.V.; TULMANN NETO, A.; CASSIERI, P.; MENDES, B.M.J. Desempenho agronômico de variantes somaclonais de bananeira (Musa AAA), micropropagadas da cultivar Grande naine. In: CONGRESSO BRASILEIRO DE FRUTICULTURA, 15., 1998, Poços de Caldas-MG. Anais... Sociedade Brasileira de Fruticultura e Universidade Federal de Lavras, 1998. p. 108.

SALOMÃO, L.C.C.; PEREIRA, M.C.T.; SEDIYMA, C.S.; COUTO, F.A.D.A Crescimento e produção de primeiro ciclo de bananeira (Musa spp.) 'Prata-anã' em sete espaçamentos, em Visconde de Rio Branco-MG. In: CONGRESSO BRASILEIRO DE FRUTICULTURA, 15., 1998, Poços de Caldas-MG. Resumos... Lavras: UFLA/SBF, 1998. p.131.

SOUZA, A. da S.; CORDEIRO, Z.J.M.; TRINDADE, A.V. Produção de mudas. In: CORDEIRO, Z.J.M. Banana Produção: aspectos técnicos. Brasília:Embrapa Comunicação para Transferência de Tecnologia, 2000. p. 39-46.

TEIXEIRA, L.A.J. Bananeira (Musa spp). In: MELETTI, L.M.M. Propagação de frutíferas tropicais. Guaíba: Agropecuária, 2000. p. 105-124.

VULSTEKE, D.; ORTIZ, R. Field performance of conventionalvs. In vitro propagules of plantain (Musa spp., AAB group). HortScience, Alexandria, v.31, n.5, p.862-865, 1996.

www.multiplanta.com.br Mudas de bananeira.info@multiplanta.com.br acessado em 21-05-2001. 18h29. 